\title{
Long-delay learning of a black-white discrimination: Effect of varying the length of delay
}

\author{
BOW TONG LETT \\ Memorial University of Newfoundland, St. John's, Newfoundland A1C 5S7, Canada
}

\begin{abstract}
Visual discrimination learning with a 1-min delay of reward has been demonstrated in rats with a procedure in which the delay is spent in the home cage (Lett, 1974). Two of the present experiments studied the effect of varying the length of delay on such visual discrimination learning. In Experiment 1, different groups of rats were trained with a delay of reward lasting $30,60,120$, or $240 \mathrm{sec}$. All groups learned the discrimination. Although the group delayed for $30 \mathrm{sec}$ appeared to perform better than the other groups, the main statistical analysis yielded no reliable difference in performance among groups. It seemed possible, however, that a delay gradient might be more readily detected when very short delays are studied. In Experiment 2, three groups of rats were trained with delays lasting 0,10 , or $60 \mathrm{sec}$; the results were that the 0-sec delay group performed better than the 10-sec delay group, which in turn performed better than the 60-sec delay group. Experiment 3 attempted to ascertain whether a parallel gradient would be obtained in spatial discrimination learning under the home-cage delay procedure. Three groups of rats were trained in a spatial discrimination with delays lasting 0,10 , or $60 \mathrm{sec}$. Superior performance was exhibited by the rats in the 0 -sec delay condition, but there was no significant difference in performance between those delayed for 10 and $60 \mathrm{sec}$.
\end{abstract}

Lett $(1973,1974)$ has shown that rats can learn a spatial or visual discrimination in a T-maze with a 1-min delay of reward. The distinctive feature of these experiments was that the rat spent the delay of reward outside the T-maze in its own home cage. After the rat entered a choice alley, whether correct or incorrect, it was removed and placed in its home cage. When the delay ended, the rat was returned to the startbox of the T-maze, where it received feedback for its choice response.

In the spatial discrimination experiments with the home-cage delay (HCD) procedure, the rats showed signs of learning with a 1-min delay within 20 trials and were making $90 \%$ correct responses within 70 trials. Furthermore, there was no significant difference in overall performance between rats trained with delays of 30,60 , 120 , and $480 \mathrm{sec}$ (Lett, 1973) or between rats trained with delays of 1,20 , or $60 \mathrm{~min}$ (Lett, 1974).

In contrast, HCD learning of the visual discrimination was prolonged and final performance was relatively poor after 100 days of training. Roberts' (1976) failure to obtain clear-cut visual discrimination learning with a 1-min delay using a procedure similar to Lett's (1974) corroborates the difficulty of such a discrimination problem for rats. Thus, it seems possible that HCD learning of visual discrimination, unlike spatial discrimination, yields a delay gradient in which learning declines

This research was supported by National Research Council of Canada Grant A8270. I am grateful to S. Revusky for reading this paper and to A. Dawe for technical assistance. Reprint requests should be sent to Bow Tong Lett, Department of Psychology, Memorial University of Newfoundland, St. John's, Newfoundland, A1C 5S7, Canada. to near zero with delays of just 1 or $2 \mathrm{~min}$. To test this possibility, in Experiment 1, different groups of rats were trained in a visual discrimination with delays of reward lasting $30,60,120$, or $240 \mathrm{sec}$.

\section{EXPERIMENT 1}

\section{Method}

Subjects. Forty adult male albino rats were gradually reduced to $80 \%$ of free-feeding weights prior to the start of training. During training, they were maintained on limited amounts of feed so that they gained only a few grams each week; water was continuously available.

Apparatus. The T-maze was similar to that used by Lett (1974) except it had one-way doors operated by the animal (rather than guillotine doors operated by the experimenter). Briefly, the T-maze consisted of a gray startbox $(30.5 \times 17.8 \times 15.2 \mathrm{~cm})$ with a black endbox $(33.0 \times 12.7 \times 15.2 \mathrm{~cm})$ on one side and a white endbox of the same dimensions on the other side. Transparent one-way doors, hinged from the top, permitted entry into the endboxes and prevented retracing. A thin metal rod could be put across each door to lock an animal in the startbox. The walls of the various compartments were made of painted wood. The lids were made of transparent plastic; however, the lid of the black endbox was partly covered with black plastic tape to darken this box still further. The floors were made of hardware cloth.

Procedure. During a preliminary phase, the rats were extensively handled; on several occasions they were placed in groups of 10-15 on a small open field and allowed to explore. The purpose of these treatments was to reduce emotionality in novel situations. On each of the 2 days immediately prior to the start of training, each rat was placed in the locked startbox and allowed to consume $2.5 \mathrm{ml}$ of sucrose solution $(25 \% \mathrm{w} / \mathrm{v})$ from a small dish. The rats were then randomly divided into four groups and trained in a visual discrimination with a delay of reward lasting $30,60,120$, or $240 \mathrm{sec}$; this delay was measured between removal from the endbox and replacement in the startbox. For half of the animals in each group, entry into the black endbox 
was rewarded after the appropriate delay; for the remainder, a response to the white endbox was rewarded. The positions of the black and white endboxes remained fixed within a training day, but between days the boxes were semirandomly alternated so that, within every block of 10 days, each of the endboxes appeared on a particular side of the startbox equally often.

Each day's training consisted of a single rewarded trial preceded by as many incorrect responses as the animal made. At the start of each training session, the rat was introduced into the startbox and could freely enter either endbox by pushing through a one-way door. The choice response was considered completed when the door closed behind the rat. Whether the response was correct or incorrect, the rat was then removed and placed in its home cage to spend the appropriate delay interval. At the end of the delay, the rat was returned to the startbox. If its choice had been incorrect, the startbox was empty and the rat was allowed to make another choice response. This procedure was repeated until the rat made the correct choice. Following a correct choice, the rat found the dish containing $2.5 \mathrm{ml}$ of sucrose solution in the locked startbox. Training terminated each day after the rat consumed its reward. Approximately $30 \mathrm{~min}$ later, the rat was given its daily ration of chow pellets in its home cage. The rats were trained for 80 days.

Early in training, some of the rats failed to enter an endbox. A rat was allowed $1,000 \mathrm{sec}$ during the first 10 days of training and 2,000 sec thereafter before it was guided by the experimenter into the correct endbox. After a guided response, the rat was treated as if it had voluntarily made the correct response. That is, following the appropriate delay in the home cage, the rat was returned to the locked startbox, where it was given $2.5 \mathrm{ml}$ of sucrose solution. In all, 8 of the 40 rats had to be guided one or more times; no guided responses occurred after Day 12.

Data analysis. Only the first-choice response of each day was used in the data analysis. For each rat, the percentage of correct first-trial responses during each block of 10 days was computed with a guided response counted as .5 of a correct response. These data were subjected to a 4 by 2 by 8 analysis of variance with repeated measures (Winer, 1962) in which one factor was length of.delay $(30,60,120$, or $240 \mathrm{sec})$, the second factor was type of rewarded endbox (black or white), and the third factor was block of 10 days.

\section{Results and Discussion}

Figure 1 shows the percentage of correct responses during each block of 10 days for each delay group. Although Figure 1 suggests that the animals delayed for $30 \mathrm{sec}$ performed better than those delayed for longer intervals, the analysis of variance did not yield a significant effect of delay length on overall performance $(.10<p<.20) .^{1}$ The only significant effect was that the percentage of correct responses increased over blocks $[F(7,224)=16.80, p<.001]$, indicating that the animals did learn the visual discrimination. This conclusion was further supported by the presence of significant linear trends over blocks in each group when considered separately $[\mathrm{F}(1,224)=63.20, \mathrm{p}<.001,30$-sec group; $F(1,224)=7.60, p<.01,60$-sec group $F(1,224)=16.00$, $\mathrm{p}<.001,120$-sec group: $\mathrm{F}(1,224)=33.60, \mathrm{p}<.001$, 240-sec group].

These results suggest that HCD learning of a visual discrimination might occur with delays substantially longer than $4 \mathrm{~min}$. Although it has been possible to show that rats can learn a spatial discrimination with a delay lasting $1 \mathrm{~h}$ (Lett, 1975), unpublished work in my laboratory has not provided a clear answer to the question of

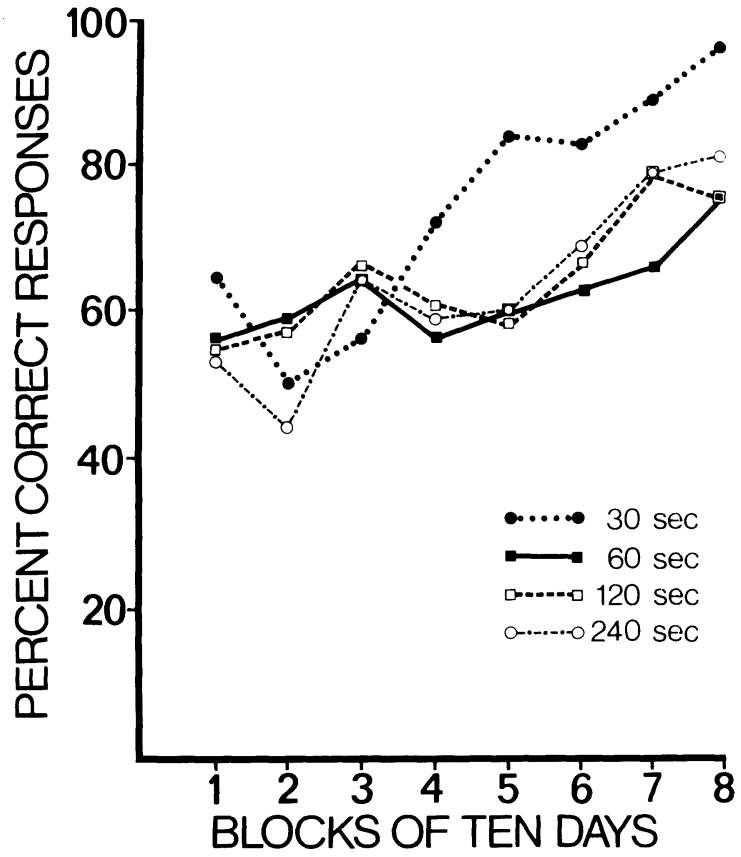

Figure 1. Percentage of correct first-trial responses in blocks of $\mathbf{1 0}$ days for rats trained in a visual discrimination with a delay of reward lasting $30,60,120$, or $240 \mathrm{sec}$.

whether HCD learning of a visual discrimination can occur with a 1 -h delay.

\section{EXPERIMENT 2}

Similar to the results obtained in an earlier spatial discrimination experiment (Lett, 1973), varying the length of delay from $30 \mathrm{sec}$ to 4 min did not produce a clear-cut effect on visual discrimination performance in Experiment 1. The direction of the results suggested, however, that a differential effect of delay length might be detected with very short delays. Therefore, three groups of rats were trained in a visual discrimination with delays of reward lasting 0,10 , or $60 \mathrm{sec}$.

\section{Method}

Subjects. Thirty-six adult male albino rats were gradually reduced to $80 \%$ of their free-feeding weights; one died during the course of training, and its data were excluded from the statistical analysis. Prior to the start of training, these rats, like those in Experiment 1, were allowed to explore in an open field and were given two exposures to the reward substance in the startbox.

Procedure. The procedure was similar to that used in Experiment 1, but some modifications were needed to accommodate the 0-sec delay condition. In the 0-sec delay group, the rat was not placed in the home cage after a choice response. As soon as the one-way door fell behind the animal, thin rods were pushed across each door to lock it. (In previous experiments, all of which involved delays of $30 \mathrm{sec}$ or more, the rods were inserted, if appropriate, during the delay while the rat was in its home cage.) Although locking the startbox doors is necessary only when the rat is to be rewarded, the rods were inserted after correct and incorrect responses to insure that feedback for the response was restricted to the startbox. After locking the doors, the experimenter picked up the rat. Following a correct response, the 
experimenter inserted first the dish of sugar water and then the rat into the startbox. Following an incorrect choice, the rods were removed; then the rat was placed back into the startbox and allowed to make another choice. When the time needed for experimental manipulations is taken into consideration, the length of delay in the 0 -sec delay condition, as measured between removal from the endbox and replacement in the startbox, was about 2 sec.

To make the procedures for the three groups as much alike as possible, the doors were always locked before any rat was removed from the endbox. In all other respects, the procedure was the same as that described in Experiment 1. The rats were trained in this fashion for 50 days.

Data analysis. The data were treated in the manner described in Experiment 1. In Experiment 2, 12 rats had to be guided one or more times; however, only 1 rat had to be guided on some occasions past Day 10 of training.

\section{Results}

Figure 2 shows the percentage of correct first-trial responses during each block of 10 days for each delay group. All groups learned the discrimination, as evidenced by a significant blocks effect when all groups are considered together $[F(4,116)=17.31, p<.001]$ and by significant linear trends when each group is considered separately $[F(1,116)=38.85, \mathrm{p}<.001,0$-sec group; $F(1,116)=20.38, p<.001,10$-sec group; $F(1,116)=$ $11.15, \mathrm{p}<.01,60$-sec group]. The groups did differ, however, in overall percentage of correct responses $[F(2,29)=9.00, p<.001]$; the animals in the 0 -sec delay group made more correct responses than those delayed for $10 \mathrm{sec}[\mathrm{F}(1,29)=12.64, \mathrm{p}<.001]$ or for $60 \mathrm{sec}[\mathrm{F}(1,29)=92.77, \mathrm{p}<.001]$, and the 10-sec delay group made more correct responses than those delayed

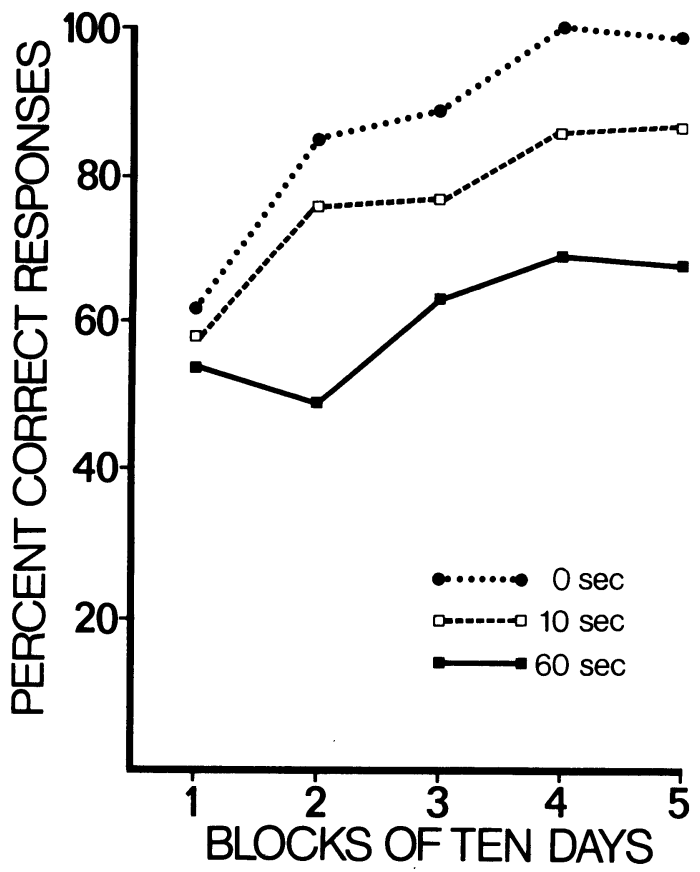

Figure 2. Percentage of correct first-trial responses in blocks of $\mathbf{1 0}$ days for rats trained in a visual discrimination with a delay of reward lasting 0,10 , or $60 \mathrm{sec}$. for $60 \mathrm{sec}[F(1,29)=34.44, p<.001]$. None of the effects involving type of rewarded endbox or interactions was statistically significant.

\section{EXPERIMENT 3}

Experiment 2 yielded a differential effect of delay on visual discrimination learning with delay lengths of 0,10 , or $60 \mathrm{sec}$. Experiment 3 attempted to discover whether a similar effect occurs in spatial discrimination learning.

\section{Method}

Subjects. Twenty-nine male albino rats were prepared for training in the same way as those in Experiments 1 and 2.

Apparatus. The T-maze was the same as that used in Experiments 1 and 2 except that the lid of the black endbox was not partly covered with black tape; the endboxes remained in a fixed position with the white endbox on the left and the black endbox on the right.

Procedure. The rats were randomly assigned to three groups; 10 rats were trained with a 0 -sec delay, 9 with a 10-sec delay, and 10 with a 60 -sec delay. In each group, five rats were rewarded for entering the left endbox and the remainder for entering the right endbox. The rats were trained for 30 days. In all other respects, the procedure was the same as that of Experiment 2. As in the two preceding experiments, some rats balked during the early part of training. Four rats had to be guided on one or more occasions, but no guided responses occurred after the sixth day of training.

Data analysis. For each rat, the percentage of correct first-trial responses during each block of 5 days (rather than 10 days) was computed; as before, guided responses counted as .5 of a correct response. These data were initially subjected to a 3 by 2 by 6 analysis of variance with repeated measures, in which one factor was length of delay $(0,10$, or $60 \mathrm{sec})$, a second factor was side of rewarded response (left or right), and the third was block of 5 days. This analysis, however, yielded an irrelevant complication in the form of a Side by Delay by Block interaction $(p<.01)$ and reflected the inexplicable fact that side-preference effects on learning differed among the various groups. In the 10-sec delay condition, the rats rewarded for a right turn learned, while those rewarded for a left turn did not; the reverse was true in the 60-sec delay condition, while the rats in the 0-sec delay condition learned whether rewarded for a right- or a left-choice response. Since side of rewarded choice had no consistent effect across the various groups and was not a variable of theoretical interest, these data were subjected to a second analysis of variance, similar to the first, except that side of rewarded choice was not a factor. The statistical values reported in the Results section were obtained from this second analysis.

\section{Results and Discussion}

Figure 3 shows the percentage of correct first-trial responses during each block of 5 days for each delay group. Each group learned the discrimination, as evidenced by a significant effect of blocks in the overall analysis of variance $[F(5,130)=9.06, p<.001]$ and significant linear trends when each group is considered separately $[\mathrm{F}(1,130)=21.44, \mathrm{p}<.001,0$-sec group; $\mathrm{F}(1,130)=5.02, \mathrm{p}<.05,10$-sec group; $\mathrm{F}(1,130)=$ $11.73, \mathrm{p}<.01,60$-sec group]. Although there was a significant difference in performance across delay groups $[F(2,26)=3.59, p<.05]$, the pattern of results was not the same as in Experiment 2; for while the 0-sec delay group made more correct responses than either the 10-sec 


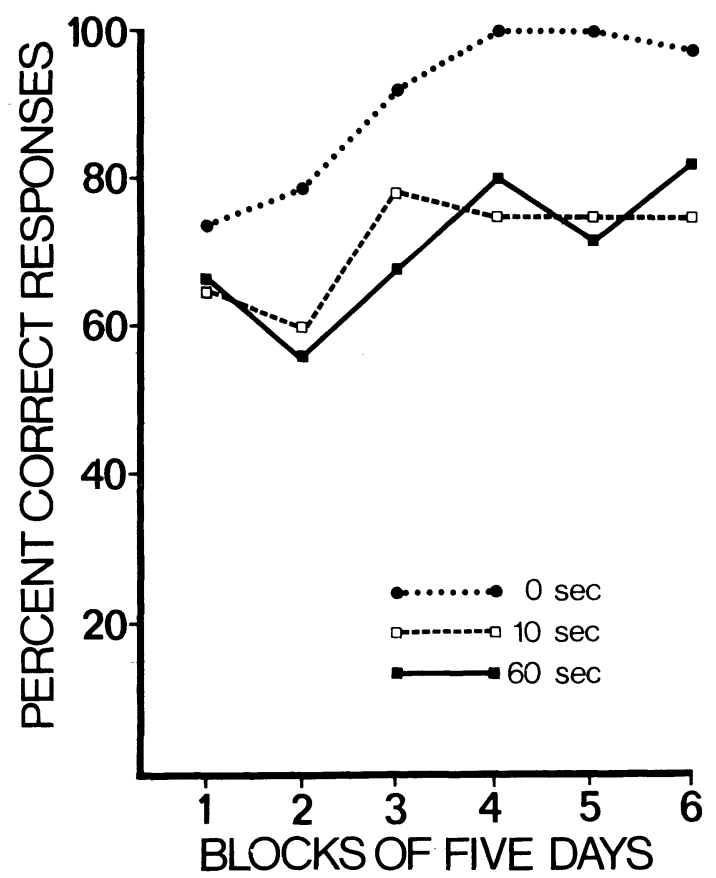

Figure 3. Percentage of correct first-trial responses in blocks of 5 days for rats trained in a spatial discrimination with a delay of reward lasting 0,10 , or $60 \mathrm{sec}$.

$[F(1,26)=30.00, \mathrm{p}<.001]$ or the 60 -sec delay group $[F(1,26)=35.05, p<.001]$, the latter groups did not differ from each other $(F<1)$. The relative superiority of the 0-sec delay group cannot be unambiguously attributed to delay length, since it might also be attributed to unavoidable differences in delay procedure. For example, the rats in the 0 -sec delay group, in contrast to the rats in the other delay conditions, were not placed in the home cage and received less handling during the delay.

\section{GENERAL DISCUSSION}

The original basis for the HCD experiment was Revusky's $(1971,1977)$ concurrent interference theory of long-delay learning. More recently, however, an alternative account (Lett, in press; Roberts, 1976) has emphasized the role of memory reactivation or retrieval in HCD learning and other, similar phenomena (e.g., Capaldi, 1971). Both of these theories tend to predict that length of delay is relatively unimportant in HCD learning, but do so for somewhat different reasons.

Concurrent interference theory assumes that the association between choice response and delayed goal outcome is subject to interference when the delay events become associated with either the response or the goal outcome. An increase in delay length is detrimental to learning only insofar as it permits an increase in the number of delay events that might become associated with the response or the goal outcome. When the delay events are made to occur outside of the T-maze, as in the HCD procedure, they are assumed to have little associative strength relative to events occurring inside the T-maze and, hence, to produce little interference with the association between a response and a delayed goal outcome. Thus length of delay over a wide range of values should not be an important determinant of learning as long as the delay events occur outside the T-maze.

In its simplest form, the reactivation theory assumes that situational stimuli provided by the training apparatus reactivate memory of events that previously occurred there. In HCD learning, memory of the choice response is assumed to be reactivated when the animal is returned to the startbox after the delay. When memory of a choice response is active at the time of reward (or nonreward), that response tends to become associated with the goal outcome. Since the stimuli provided by the T-maze tends to remain constant over time, delay length should have little effect on HCD learning.

This assumption about delay length is no longer justified. To summarize the available evidence, the function relating HCD learning and delay length can be divided into three portions. Over the range of very short delays up to approximately $1 \mathrm{~min}$, the function steeply declines; it seems likely that the slope of this portion is steeper for visual than for spatial discrimination learning. Over a broad range of intermediate delay values, the function remains well above zero learning and has a relatively flat slope; probably this intermediate portion extends over a wider range of delay values for spatial than for visual discrimination learning. With extremely long delays, of course, the function probably declines to zero learning.

Both concurrent interference theory and reactivation theory, in their present forms, provide reasonable accounts of the intermediate portion of the suggested delay function; with the addition of a few simple assumptions, either can be made to account for the initial and final portions also. For example, to explain the initial portion, it might be assumed that the memory trace of the visual (but perhaps not the spatial) attributes of the choice compartments declines to some stable nonzero value within the first minute. There are other possibilities, but it would be inappropriate to speculate further, since the present findings do not provide any information about them.

\section{REFERENCES}

CAPaldi, E. J. Memory and learning: A sequential viewpoint. In W. K. Honig \& P. H. R. James (Eds.), Animal memory. New York: Academic Press, 1971. Pp. 111-154.

LETT, B. T. Delayed reward learning: Disproof of the traditional theory. Learning and Motivation, 1973, 4, 237-246.

LETT, B. T. Visual discrimination learning with a 1-min delay of reward. Learning and Motivation, 1974, 5, 174-181.

LETT, B. T. Long delay learning: Implications for learning and memory theory. In N. S. Sutherland (Ed.), Tutorial essays in experimental psychology (Vol. 2). Hillsdale, N.J: Erlbaum, in press.

REVUSKY, S. The role of interference in association over a delay. In W. K. Honig \& P. H. R. James (Eds.), Animal memory. New York: Academic Press, 1971. Pp. 155-213.

REvusky, S. The concurrent interference approach to delay learning. In L. M. Barker, M. R. Best, \& M. Domjan (Eds.), Learning mechanisms in food selection. Waco, Tex: Baylor University Press, 1977.

Roberts, W. A. Failure to replicate visual discrimination learning with a 1-min delay of reward. Learning and Motivation, 1976, 7, 313-325.

WINER, B. J. Statistical principles in experimental design. New York: McGraw-Hill, 1962.

\section{NOTE}

1. It is worth noting that there was a significant linear trend across delay groups $[F(1,32)=12.53, p<.01]$, suggesting that the overall percentage of correct responses declined as length of delay increased. The outcome of the trend test is reported only as a point of information, since it might be considered inappropriate to do such a test after the analysis of variance has yielded a nonsignificant delay effect.

(Received for publication July 6, 1978.) 